\title{
Stereotactic laser ablation for hypothalamic and deep intraventricular lesions
}

\author{
Robert T. Buckley, MD, ${ }^{1}$ Anthony C. Wang, MD, ${ }^{1}$ John W. Miller, MD, PhD, ${ }^{3}$ \\ Edward J. Novotny, MD, ${ }^{1-3}$ and Jeffrey G. Ojemann, MD'1 \\ Divisions of ${ }^{1}$ Neurological Surgery and ${ }^{2}$ Pediatric Neurology, Seattle Children's Hospital; and ${ }^{3}$ Department of Neurology, \\ University of Washington School of Medicine, Seattle, Washington
}

\begin{abstract}
OBJECTIVE Laser ablation is a novel, minimally invasive procedure that utilizes MRI-guided thermal energy to treat epileptogenic and other brain lesions. In addition to treatment of mesial temporal lobe epilepsy, laser ablation is increasingly being used to target deep or inoperable lesions, including hypothalamic hamartoma $(\mathrm{HH})$, subependymal giant cell astrocytoma (SEGA), and exophytic intrinsic hypothalamic/third ventricular tumors. The authors reviewed their early institutional experience with these patients to characterize clinical outcomes in patients undergoing this procedure.

METHODS A retrospective cohort $(n=12)$ of patients undergoing laser ablation at a single institution was identified, and clinical and radiographic records were reviewed.

RESULTS Laser ablation was successfully performed in all patients. No permanent neurological or endocrine complications occurred; 2 (17\%) patients developed acute obstructive hydrocephalus or shunt malfunction following treatment. Laser ablation of $\mathrm{HH}$ resulted in seizure freedom (Engel Class I) in 67\%, with the remaining patients having a clinically significant reduction in seizure frequency of greater than $90 \%$ compared with preoperative baseline (Engel Class IIB). Treatment of SEGAs resulted in durable clinical and radiographic tumor control in 2 of 3 cases, with one patient receiving adjuvant everolimus and the other receiving no additional therapy. Palliative ablation of hypothalamic/third ventricular tumors resulted in partial tumor control in 1 of 3 patients.

CONCLUSIONS Early experience suggests that laser ablation is a generally safe, durable, and effective treatment for patients harboring HHs. It also appears effective for local control of SEGAs, especially in combination therapy with everolimus. Its use as a palliative treatment for intrinsic hypothalamic/deep intraventricular tumors was less successful and associated with a higher risk of serious complications. Additional experience and long-term follow-up will be beneficial in further characterizing the effectiveness and risk profile of laser ablation in treating these lesions in comparison with conventional resective surgery or stereotactic radiosurgery.

http://thejns.org/doi/abs/10.3171/2016.7.FOCUS16236
\end{abstract}

KEY WORDS laser ablation; epilepsy; hypothalamic hamartoma; subependymal giant cell astrocytoma

$\mathrm{S}$ TEREOTACTIC laser ablation is a recently developed surgical technique that offers a targeted, minimally invasive approach for management of focal intracranial lesions. The development of practical MR thermometry to allow real-time temperature monitoring during lesioning means that laser ablation has a marked advantage over previous stereotactic radiofrequency techniques due to its ability to tailor thermal energy deposition and prevent injury to adjacent cortical and deep structures. ${ }^{23}$ This has led to rapid utilization of stereotactic laser ablation in the neurosurgical community for treatment of inaccessible and/or high-risk lesions.
Initial neurosurgical experience with stereotactic laser ablation was focused on patients with intractable mesial temporal lobe epilepsy; stereotactic laser amygdalohippocampotomy (SLAH) consists of a highly selective functional disconnection of the hippocampus and amygdala without the need for resection of intervening temporal neocortex. ${ }^{5}$ The minimally invasive approach of SLAH offers the benefit of minimizing the risk of neuropsychological deficits after surgery, especially with treatment of dominant mesial temporal lobe epilepsy, as well as offering an alternative treatment modality for patients unable or unwilling to undergo standard open anterior temporal

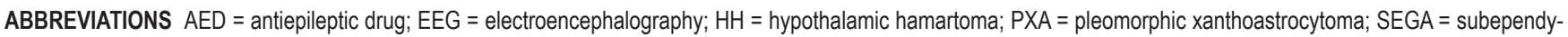
mal giant cell astrocytoma; SLAH = stereotactic laser amygdalohippocampotomy; VP = ventriculoperitoneal.

SUBMITTED June 2, 2016. ACCEPTED July 25, 2016.

INCLUDE WHEN CITING DOI: 10.3171/2016.7.FOCUS16236. 
lobectomy. Initial experience in pediatric and adult patients suggests similar or slightly lower seizure freedom rates when compared with anterior temporal lobectomy and lower rates of serious complications and postoperative naming deficits. ${ }^{2,5,6,25}$ With these early favorable results, stereotactic laser ablation is being used for a wide array of indications, including brain metastases, ${ }^{4,9}$ recurrent and primary gliomas, ${ }^{3,19}$ periventricular nodular heterotopia, ${ }^{7}$ hypothalamic hamartomas (HHs), ${ }^{22,24}$ and radiation necrosis. ${ }^{20}$

In addition, there is significant interest in the potential utility of stereotactic laser ablation for the treatment of hypothalamic and deep intraventricular lesions, in the hope that it may offer similar benefits in regard to minimizing postoperative complications and neuropsychological deficit.

Hypothalamic hamartomas are congenital neuroglial lesions that typically present with intractable epilepsy and/ or precocious puberty. Gelastic seizures are characterized by so-called "mirthless laughter" and alterations in consciousness; they are notoriously difficult to treat with antiepileptic drugs (AEDs). Current surgical treatment includes open and endoscopic resection and/or disconnection, resulting in a 50\%-65\% seizure freedom rate and up to a $25 \%$ rate of permanent complication, ${ }^{8,14-16,18}$ while radiosurgery is associated with a complete seizure freedom rate of less than $40 \% .{ }^{21}$ Early experience from Wilfong and Curry suggested that stereotactic laser ablation may offer both improved seizure control and fewer complications when compared with standard therapies. ${ }^{24}$

Subependymal giant cell astrocytomas (SEGAs) are low-grade (WHO Grade I) infiltrative glial neoplasms that are classically associated with tuberous sclerosis and seen most frequently arising at the foramen of Monro. While the lesion itself is typically characterized as benign, SEGAs can cause symptoms due to obstructive hydrocephalus or direct invasion of critical deep brain structures, such as the thalamus, hypothalamus, and basal ganglia. Treatment is usually via open or endoscopic resection, and in tumors that are surgically accessible this is generally curative. However, in incompletely resected SEGAs, up to $100 \%$ reoperation rates are noted. ${ }^{1}$ Radiosurgery has also been used for inoperable tumors with reported long-term control rates of $67 \%,{ }^{17}$ and recent introduction of everolimus, an mTOR inhibitor, has provided new options for medical management. ${ }^{13}$ Again, there exists a potential role for laser ablation for management of inoperable, symptomatic SEGAs, especially with its potential to reduce tumor volume and improve associated mass effect and/or CSF outlet obstruction.

In an effort to provide additional clinical data to evaluate the use of stereotactic laser ablation for these hypothalamic and deep intraventricular lesions, we report a retrospective analysis of our institutional cohort of these patients.

\section{Methods}

\section{Patient Selection}

We retrospectively identified 12 patients who underwent laser ablation for treatment of $\mathrm{HH}$, SEGA, or exophytic glial or neuroglial hypothalamic/third ventricular tumors at Seattle Children's Hospital from 2012 to the present and who had clinical and/or radiographic followup available for review.

\section{Laser Ablation}

All patients underwent laser ablation using the Visualase (Medtronic) system. The laser catheter was placed using stereotactic guidance via the CRW (Integra) frame in the operating room after induction of general anesthesia; target coordinates were determined using a preoperative registration MRI scan and the Framelink (Medtronic) software. After placement, real-time MR thermometry was performed using a Siemens 3-T MRI scanner, and ablation was performed using the Visualase workstation under direction of the senior author (J.G.O.). After treatment, postablation MRI sequences were obtained, the catheter was removed, and the patient was observed in the hospital.

\section{Clinical and Radiographic Review}

Review of clinical and radiographic data was performed with approval from the Seattle Children's Hospital Institutional Review Board. For patients with epilepsy, clinical data were used to determine age at seizure onset, duration of seizures, seizure semiology and frequency, and AEDs at the time of surgery and last clinical followup. Results of Phase I long-term electroencephalography (EEG) monitoring was also performed. MR images obtained before, during, and after laser ablation were reviewed to determine lesion size, volume, and response to treatment. Estimated lesion volumes were calculated using the assumption of ellipsoid geometry.

\section{Results}

A total of 12 patients were identified as meeting inclusion criteria. Indication for laser ablation included $\mathrm{HH}(\mathrm{n}=$ $6,50 \%)$, SEGA $(\mathrm{n}=3,25 \%)$, recurrent optic glioma $(\mathrm{n}=1$, $8.3 \%)$, hypothalamic ganglioglioma $(\mathrm{n}=1,8.3 \%)$, and hypothalamic pleomorphic xanthoastrocytoma $(n=1,8.3 \%)$. The average hospital length of stay postablation was 2 days (range $1-5$ days).

\section{Hypothalamic Hamartoma}

Six patients underwent laser ablation for HH (Table 1). The median age at treatment was 5.5 years (range 3.324.6 years), and the median clinical follow-up after laser ablation was 292 days (range 55-566 days). The median age at seizure onset was 2.2 years (range $0-13$ years), and the median duration of seizures at the time of treatment was 5.4 years (range 1.3-19.6 years). All patients carried a clinical diagnosis of medically intractable epilepsy; 1 (16.7\%) patient additionally presented with precocious puberty.

All patients demonstrated seizures consistent with gelastic semiology on long-term video EEG monitoring. Five $(83 \%)$ patients displayed additional seizure types, 3 (50\%) with secondarily generalized convulsions, 1 (16.6\%) with simple partial, complex partial, and secondarily generalized seizures, and 1 (16.6\%) with dialeptic seizures. Interictal EEG findings were notable for generalized mul- 


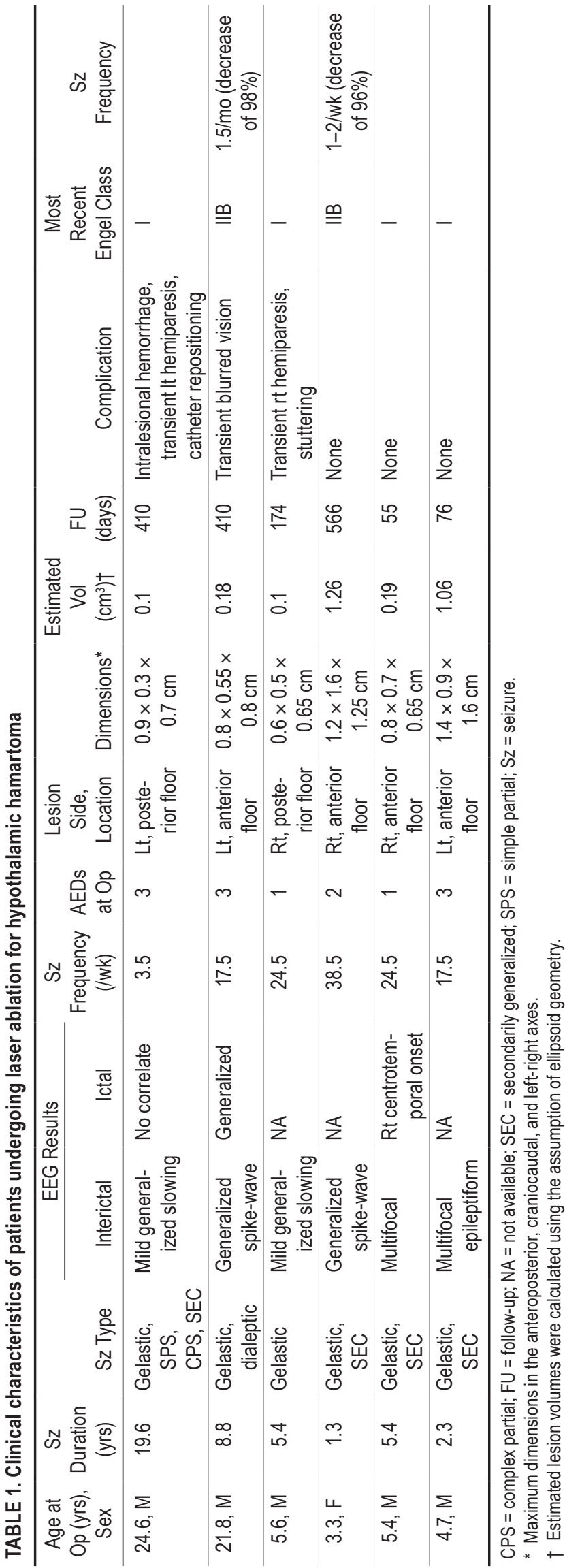

tifocal spike-wave discharges in $2(33 \%)$ patients, multifocal epileptiform discharges in $2(33 \%)$ patients, and mild generalized slowing in the remaining $2(33 \%)$ patients. Ictal EEG results were available for 3 patients and demonstrated generalized seizure in $1(33 \%)$, right centrotemporal origin in $1(33 \%)$, and no EEG correlate in $1(33 \%)$. The median number of AEDs at the time of ablation was 2.5 (range 1-3), and the median seizure frequency was 21 per week (range 3.5-38.5).

All patients underwent high-resolution MRI prior to treatment, which demonstrated a hypothalamic lesion consistent with HH (Fig. 1A). Lesions were evenly split between arising from the right or left hypothalamus. Four $(67 \%)$ had a pedunculated appearance on imaging, with the other $2(33 \%)$ having a sessile appearance. All lesions were associated with the tuber cinereum, with 4 (67\%) in the anterior portion of the third ventricle and the remaining $2(33 \%)$ in the posterior third ventricle. The median lesion dimensions were $0.85 \times 0.63 \times 0.75 \mathrm{~cm}$, and the median estimated tumor volume was $0.19 \mathrm{~cm}^{3}$ (range $0.1-1.26 \mathrm{~cm}^{3}$ ).

All patients had complete ablation of the hamartoma as determined using the Visualase thermal damage model. Three (50\%) patients had minor complications. Intralesional hemorrhage was seen in $1(16.7 \%)$ patient. One $(16.7 \%)$ patient was noted to have suboptimal placement of the laser catheter on initial MRI and underwent repositioning prior to ablation. Two (33\%) patients had transient ipsilateral weakness, consisting of profound weakness immediately postablation and rapidly resolving over 24-48 hours without residual. One (16.7\%) patient developed stuttering speech and expressive dysphasia in the setting of baseline speech delay improving with therapy on early follow-up.

Complete seizure freedom (Engel Class I) was seen in 4 (67\%) patients who had laser ablation of their HH. In these patients, there was additionally freedom from seizures of types other than gelastic if those were present prior to $a b-$ lation. Of the other 2 patients, one had initially been seizure free at the 6-month follow-up but later had recurrence of rare gelastic seizures (Engel Class IIB, $96 \%$ seizure reduction), and the other had persistent rare gelastic seizures (Engel Class IIB, 98\% seizure reduction). The median number of AEDs postablation was 2.5 drugs (range 1-3). In the 3 patients with long-term radiographic follow-up, no residual hamartoma was noted, and there was variable $\mathrm{T} 2$ and FLAIR hyperintensity in the ablation zone consistent with gliosis and encephalomalacia (Fig. 1C).

\section{Subependymal Giant Cell Astrocytoma}

Three patients underwent laser ablation for SEGA (Table 2). All patients carried the underlying diagnosis of tuberous sclerosis. The median age at treatment was 13 years (range 7.5-19 years), and the median clinical followup was 852 days (range $370-885$ days). The median age at diagnosis was 6.5 years (range 4.1-14 years), and the median duration until ablation was 5 years (range 3.4-6.5 years). Presenting symptoms were growth on serial MRI in all 3 patients; 1 (33\%) patient additionally had newonset headache, prompting early surveillance MRI. Treatment prior to laser ablation was seen in $2(67 \%)$ patients: 

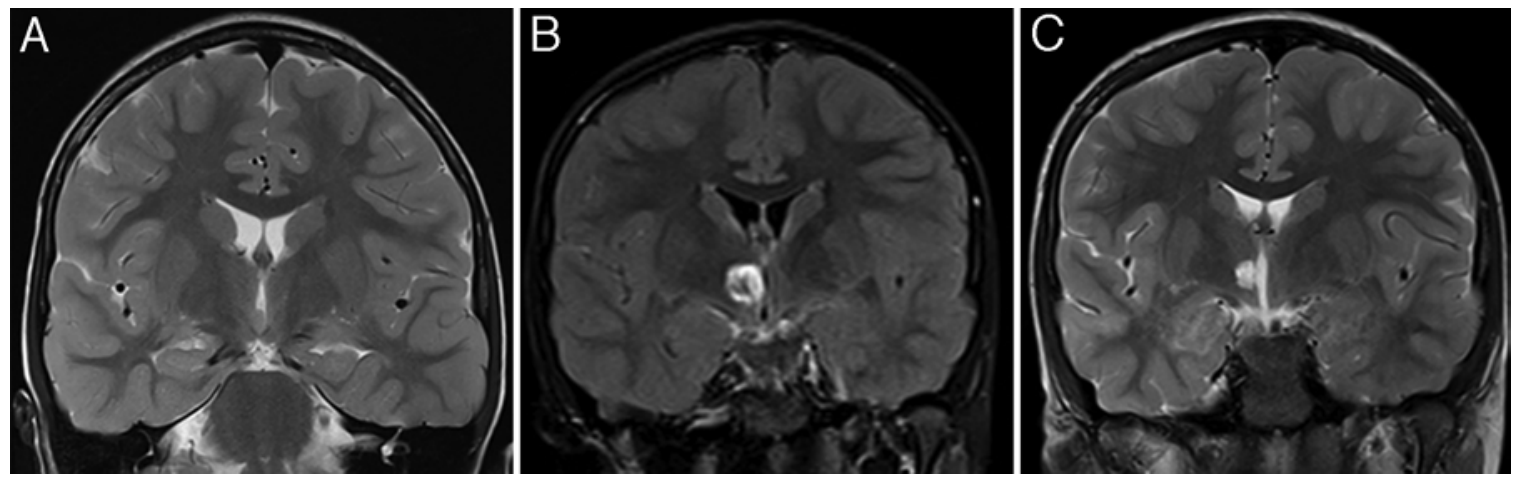

FIG. 1. Laser ablation for $\mathrm{HH}$ seen on MRI. A: Preablation high-resolution T2-weighted image demonstrating a right $\mathrm{HH}$. B: Immediate postablation T2-weighted FLAIR image demonstrating stereotypical changes consistent with successful ablation. C: Six-month postablation T2-weighted image demonstrating complete obliteration of the hamartoma.

one who had 6 weeks of neoadjuvant everolimus and the other having undergone 2 previous craniotomies for resection. Additionally, 1 patient had previously undergone craniotomy for resection of a contralateral SEGA at an outside institution.

Initial preoperative MRI demonstrated lesions consistent with SEGA at the foramen of Monro in all patients (Fig. 2A). Two (67\%) were on the right side and the other (33\%) was on the left. One (33\%) SEGA demonstrated marked calcification and 1 (33\%) patient was noted to have ventriculomegaly consistent with early obstructive hydrocephalus. The median tumor dimensions were $1.6 \times 1.6 \times$ $1.9 \mathrm{~cm}$, and the median estimated tumor volume was 4.1 $\mathrm{cm}^{3}$ (range 1.4-4.1 $\mathrm{cm}^{3}$ ).

Again, all patients had complete ablation of SEGA as determined by the thermal damage model. No procedural complications were noted. Robust reduction in tumor dimensions and volume was noted on initial follow-up MRI 3-6 months postablation in all patients (Fig. 2C), with a median relative reduction in tumor volume of $67 \%$ (range $28 \%-70 \%)$. At $12-15$ months postablation, one patient had stable reduction in tumor volume on adjuvant therapy with everolimus (60\% vs $70 \%$ reduction early postoperatively), another had further decline in tumor volume with no additional therapy (64\% vs $29 \%$ reduction early postoperatively), and the remaining patient had regrowth $(112 \%$ of original volume), necessitating initiation of everolimus.

\section{Hypothalamic/Third Ventricular Tumors}

One patient each underwent laser ablation for a hypothalamic ganglioglioma, hypothalamic pleomorphic xanthoastrocytoma (PXA), and optic glioma (Table 2). The median age at treatment was 13.9 years (range 8.8-18.4 years), and the median clinical follow-up was 272 days (range 179-683 days). The median age at diagnosis was 13.4 years (range $1.7-15.9$ years), and the median duration until ablation was 2.5 years (range $0.5-7.2$ years). In these patients the procedure was offered as a palliative measure, in contrast to patients receiving laser ablation for $\mathrm{HH}$ and SEGA.

The patient with hypothalamic ganglioglioma had previously undergone craniotomy for subtotal resection and presented with visual loss and growth on serial MRI, demonstrating a $3.1 \times 3.7 \times 3.0-\mathrm{cm}$ (maximum dimen- sions in the anteroposterior, craniocaudal, and left-right axes; estimated volume $18 \mathrm{~cm}^{3}$ ) hypothalamic mass. Laser ablation was performed and was complicated by acute postablation obstructive hydrocephalus requiring return to the operating room for septostomy and ventriculoperitoneal (VP) shunt placement. Early imaging demonstrated tumor progression (113\% of original volume) as well as a symptomatic cyst associated with the tumor that later was fenestrated via repeat craniotomy. The patient additionally was started on a regimen of drafenib after genetic testing identified the BRAF V600E mutation, with stable tumor size and volume on subsequent follow-up.

The patient with hypothalamic PXA had previously undergone stereotactic biopsy and VP shunt placement as well as multiple rounds of chemotherapy, to include vincristine/ carboplatin, thioguanine/CCNU/procarbazine/vincristine (TCPV) and bevacizumab/irinotecan. She presented with rapidly progressive right hemiparesis and MRI showing a $6.1 \times 6.0 \times 4.9-\mathrm{cm}$ (volume $94 \mathrm{~cm}^{3}$ ) hypothalamic-based mass. Laser ablation using dual catheters was performed and complicated by acute VP shunt malfunction, necessitating return to the operating room for revision. Postablation, there was continued neurological decline, and MRI demonstrated continued tumor progression $(113 \%$ of original volume). Lenalidomide was started, resulting in clinical improvement and stable tumor size and volume on subsequent imaging.

The patient with recurrent optic glioma presented with visual loss despite previous treatment including VP shunt treatment, bevacizumab plus irinotecan, and 2 craniotomies for subtotal resection at an outside institution. Laser ablation of the superior, hypothalamic/third ventricular portion of the tumor measuring $1.8 \times 2.6 \times 2.7 \mathrm{~cm}$ (volume $6.6 \mathrm{~cm}^{3}$ ) was performed using dual laser catheters; this was complicated by a delayed (approximately 24-hour) postablation hemorrhage in the ablation zone and transient worsening of a baseline visual field cut. Early postablation follow-up demonstrated a reduction in tumor volume of $80 \%$ without need for adjuvant therapy (Fig. 3).

\section{Discussion}

This study represents additional evidence supporting the use of laser ablation for hypothalamic and deep in- 


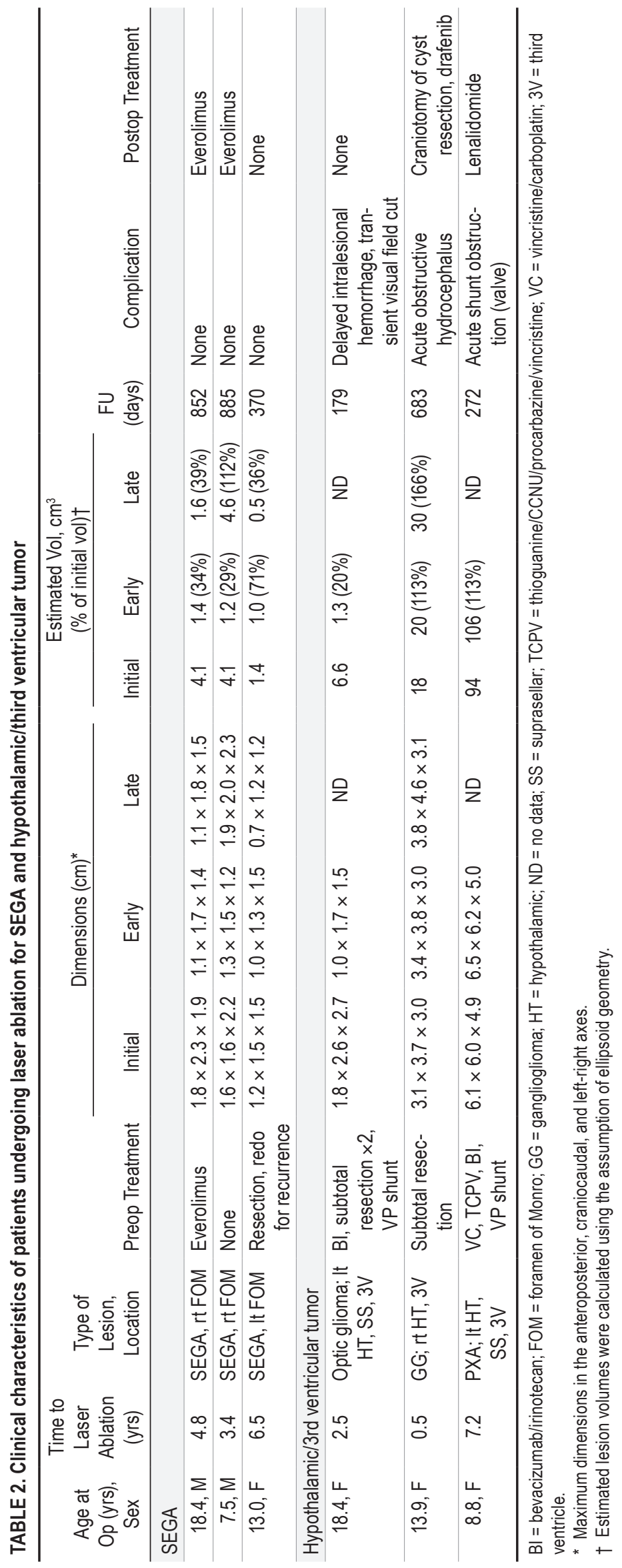



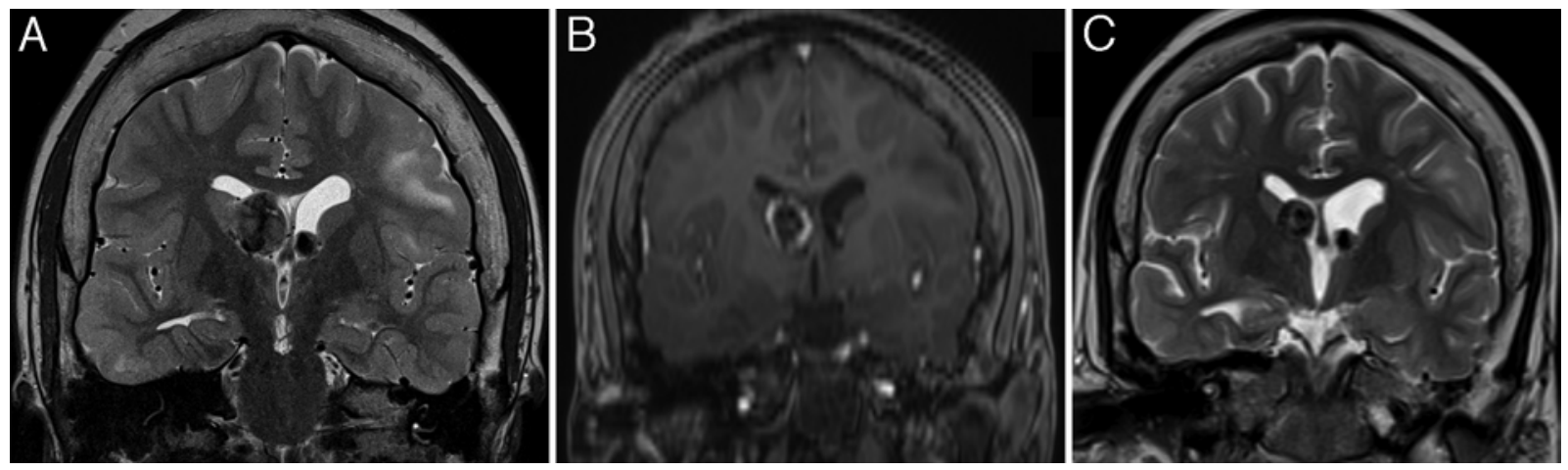

FIG. 2. Laser ablation for SEGA seen on MRI. A: Preablation T2-weighted image demonstrating an SEGA at the right foramen of Monro. Note the small lesion at the left foramen of Monro consistent with an asymptomatic SEGA. B: Immediate postablation contrast-enhanced T1-weighted image demonstrating ring enhancement consistent with successful ablation. C: T2-weighted image obtained at 21 months postablation, demonstrating durable reduction in lesion size and volume (61\% reduction).

traventricular lesions, including HHs, subependymal giant cell astrocytomas, and exophytic hypothalamic/third ventricular tumors.

The use of laser ablation for medically intractable epilepsy secondary to $\mathrm{HH}$ resulted in a good outcome (i.e., Engel Classes I and II) in all patients, with complete seizure freedom (Engel Class I). In two-thirds of patients the treatment resulted in complete seizure freedom (Engel Class I) and in the remaining one-third there were rare disabling seizures with greater than $90 \%$ reduction in seizure frequency (Engel Class IIB). These results compare favorably with the rate of similar outcomes seen in other treatment modalities, namely, the approximate 50\%-65\% rate described with conventional microsurgical and endoscopic resective surgery ${ }^{8,14,16}$ and the $60 \%$ rate described with radiosurgery. ${ }^{21}$ Our results are also comparable to recent data examining MRI-guided stereotactic radiofrequency ablation ${ }^{11}$ and early data from similar institutions utilizing laser ablation for $\mathrm{HH}$ treatment. ${ }^{24}$

No permanent neurological or endocrine complications were noted after laser ablation of $\mathrm{HHs}$ in our series. Intralesional hemorrhage was seen in $1(17 \%)$ patient. Transient neurological deficits were common (50\%), and similar rates are seen with resective surgery ${ }^{18}$ and stereo- tactic radiofrequency ablation. ${ }^{11}$ These included transient ipsilateral hemiparesis, expressive dysphasia, and blurred vision. Interestingly, in both patients with transient weakness, the hamartoma was located in the posterior third ventricle abutting the cerebral peduncle, while the patient with blurred vision harbored a hamartoma in the anterior third ventricle overlying the optic apparatus. This, along with rapid resolution and responsiveness to steroid therapy, suggests local edema and mass effect secondary to the ablation as the etiology for these symptoms.

Laser ablation for SEGA resulted in durable clinical and radiographic tumor control in two-thirds of patients in this study, although this is partially confounded, as one patient was receiving adjuvant therapy with everolimus. Overall, this rate compares similarly with rates seen after radiosurgery or everolimus alone..$^{13,17}$ No complications were noted during these treatments. While no tumor was completely extirpated after laser ablation, there were marked reductions in tumor volumes up to $70 \%$. In the patient who did not have durable radiographic tumor control, tumor volumes remained at or below preablation volumes until 15 months posttreatment.

Results for laser ablation as a palliative therapy for incompletely resectable or recurrent hypothalamic or deep
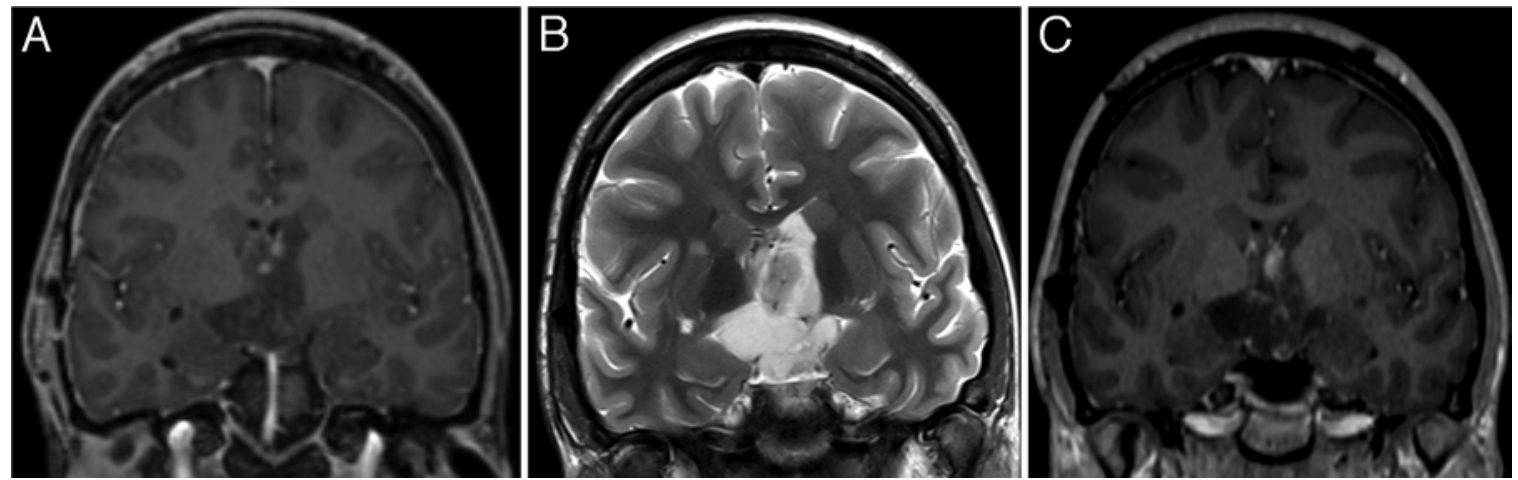

FIG. 3. Laser ablation for recurrent optic glioma. A: Preablation postcontrast T1-weighted image of a tumor involving suprasellar, hypothalamic, and third ventricular regions. B: Immediate postablation T2-weighted image. Note the central core of T2 hypointensity consistent with treatment change in the targeted hypothalamic/third ventricular portion of the tumor. C: Six-month postablation postcontrast T1-weighted image showing a decrease in size and volume of the superior portion of the tumor with residual contrast enhancement in the ablation zone. 
intraventricular tumors were more mixed, with only one patient who underwent ablation of the third ventricular portion of a recurrent optic glioma having durable radiographic tumor control. Significantly, this patient also harbored the smallest tumor in terms of tumor volume, measuring $6.6 \mathrm{~cm}^{3}$ compared with 18 and $94 \mathrm{~cm}^{3}$ in the nonresponding tumors. Achieving an acceptable cytoreductive effect in lesions of these sizes is made more difficult due to inherent limitations in the volume of thermal effect obtainable from a single catheter, ${ }^{12}$ with the preponderance of data in treatment of recurrent gliomas and metastases from tumors with volumes smaller than $10 \mathrm{~cm}^{3} \cdot 3,9,10$ To compensate for this limitation, we use multiple laser catheters to optimize lesion coverage; this may account for the more favorable response in the optic glioma patient as 2 catheters were used.

Again, no permanent neurological or endocrine complications were seen in the patients who underwent laser ablation for these hypothalamic/third ventricular tumors. Delayed intralesional hemorrhage was seen in one patient who also had a transient worsening of a baseline visual field cut. More importantly, the 2 patients with larger tumors developed acute obstructive hydrocephalus 24-48 hours after laser ablation. Both patients required a return to the operating room for management of hydrocephalus: one for septostomy and VP shunt placement and the other for revision of a previously placed VP shunt due to an obstructed valve. We believe that the shunt failure was most likely secondary to postablation edema worsening CSF outlet obstruction in patients with shunt-treated or partially compensated obstructive hydrocephalus; an additional role may be played by leakage of protein or blood products into the ventricles during catheter placement and following tumor ablation.

Overall, our initial experience with laser ablation for the treatment of hypothalamic and deep intraventricular lesions is favorable.

Treatment of intractable epilepsy secondary to HHs appears most promising, with most patients becoming seizure free after ablation and all patients achieving at least $90 \%$ reduction in seizure frequency. Permanent neurological complications appear markedly reduced, and transient complication rates are at least equivalent to other treatment methods. Hospital length of stay is markedly reduced, averaging 2 days in our series. Additionally, we expect the complication rate to be further reduced as our and other institutions gain more experience with laser ablation; indeed, our experience in the more numerous SLAH population bears this out (unpublished data).

Use of laser ablation for treatment of SEGAs in the context of patients with tuberous sclerosis also shows promise. It is especially attractive in those patients who cannot tolerate open resective surgery or chemotherapy due to their associated side effects or underlying medical comorbidities. Results for incompletely resectable hypothalamic and third ventricular lesions are mixed, with tumor control appearing to negatively correlate with tumor size and higher rates of serious complication. Tumor control for lesions with volumes greater than $10 \mathrm{~cm}^{3}$ appears unsatisfactory, even when utilizing multiple laser catheters; this is likely secondary to inherent technical and anatomical limitations when using laser thermal energy delivery in and around deep, eloquent structures. Regardless, in patients who are symptomatic and have exhausted all other options for surgery, chemotherapy, and/or radiation treatment, its use as palliation should be considered after realistic assessment of the risk/benefit ratio for the individual patient.

This series is limited by the number of patients and length of follow-up; this is unavoidable with the use of a novel treatment modality for rare lesions. Additional studies, preferably multiinstitutional, will be critical in better analyzing long-term outcomes and risks associated with laser ablation for these lesions.

\section{Conclusions}

Early experience with laser ablation in the treatment of hypothalamic and deep intraventricular lesions is encouraging, with the excellent seizure freedom or control after treatment of HHs especially promising. Permanent neurological and endocrine complications were not seen, and the transient complication rate was similar to other treatment modalities. Follow-up studies examining laser ablation for these lesions will be helpful to neurological surgeons and their patients when examining treatment options.

\section{References}

1. Beaumont TL, Limbrick DD, Smyth MD: Advances in the management of subependymal giant cell astrocytoma. Childs Nerv Syst 28:963-968, 2012

2. Buckley R, Estronza-Ojeda S, Ojemann JG: Laser ablation in pediatric epilepsy. Neurosurg Clin N Am 27:69-78, 2016

3. Carpentier A, Chauvet D, Reina V, Beccaria K, Leclerq D, McNichols RJ, et al: MR-guided laser-induced thermal therapy (LITT) for recurrent glioblastomas. Lasers Surg Med 44:361-368, 2012

4. Carpentier A, McNichols RJ, Stafford RJ, Guichard JP, Reizine D, Delaloge S, et al: Laser thermal therapy: real-time MRI-guided and computer-controlled procedures for metastatic brain tumors. Lasers Surg Med 43:943-950, 2011

5. Curry DJ, Gowda A, McNichols RJ, Wilfong AA: MR-guided stereotactic laser ablation of epileptogenic foci in children. Epilepsy Behav 24:408-414, 2012

6. Drane DL, Loring DW, Voets NL, Price M, Ojemann JG, Willie JT, et al: Better object recognition and naming outcome with MRI-guided stereotactic laser amygdalohippocampotomy for temporal lobe epilepsy. Epilepsia 56:101113,2015

7. Esquenazi Y, Kalamangalam GP, Slater JD, Knowlton RC, Friedman E, Morris SA, et al: Stereotactic laser ablation of epileptogenic periventricular nodular heterotopia. Epilepsy Res 108:547-554, 2014

8. Harvey AS, Freeman JL, Berkovic SF, Rosenfeld JV: Transcallosal resection of hypothalamic hamartomas in patients with intractable epilepsy. Epileptic Disord 5:257-265, 2003

9. Hawasli AH, Bandt SK, Hogan RE, Werner N, Leuthardt EC: Laser ablation as treatment strategy for medically refractory dominant insular epilepsy: therapeutic and functional considerations. Stereotact Funct Neurosurg 92:397-404, 2014

10. Jethwa PR, Barrese JC, Gowda A, Shetty A, Danish SF: Magnetic resonance thermometry-guided laser-induced thermal therapy for intracranial neoplasms: initial experience. Neurosurgery 71 (1 Suppl Operative):133-145, 2012

11. Kameyama S, Shirozu H, Masuda H, Ito Y, Sonoda M, Akazawa K: MRI-guided stereotactic radiofrequency thermocoagulation for 100 hypothalamic hamartomas. J Neurosurg 124:1503-1512, 2016 
12. Kangasniemi M, McNichols RJ, Bankson JA, Gowda A, Price RE, Hazle JD: Thermal therapy of canine cerebral tumors using a $980 \mathrm{~nm}$ diode laser with MR temperature-sensitive imaging feedback. Lasers Surg Med 35:41-50, 2004

13. Krueger DA, Care MM, Agricola K, Tudor C, Mays M, Franz DN: Everolimus long-term safety and efficacy in subependymal giant cell astrocytoma. Neurology 80:574-580, 2013

14. Mittal S, Mittal M, Montes JL, Farmer JP, Andermann F: Hypothalamic hamartomas. Part 2. Surgical considerations and outcome. Neurosurg Focus 34(6):E7, 2013

15. Mottolese C, Stan H, Bret P, Berlier P, Lapras C: Hypothalamic hamartoma: the role of surgery in a series of eight patients. Childs Nerv Syst 17:229-238, 2001

16. Ng YT, Rekate HL, Prenger EC, Chung SS, Feiz-Erfan I, Wang NC, et al: Transcallosal resection of hypothalamic hamartoma for intractable epilepsy. Epilepsia 47:1192-1202, 2006

17. Park KJ, Kano H, Kondziolka D, Niranjan A, Flickinger JC, Lunsford LD: Gamma Knife surgery for subependymal giant cell astrocytomas. J Neurosurg 114:808-813, 2011

18. Polkey CE: Resective surgery for hypothalamic hamartoma. Epileptic Disord 5:281-286, 2003

19. Rahmathulla G, Recinos PF, Kamian K, Mohammadi AM, Ahluwalia MS, Barnett GH: MRI-guided laser interstitial thermal therapy in neuro-oncology: a review of its current clinical applications. Oncology 87:67-82, 2014

20. Rahmathulla G, Recinos PF, Valerio JE, Chao S, Barnett GH: Laser interstitial thermal therapy for focal cerebral radiation necrosis: a case report and literature review. Stereotact Funct Neurosurg 90:192-200, 2012

21. Régis J, Scavarda D, Tamura M, Nagayi M, Villeneuve N, Bartolomei F, et al: Epilepsy related to hypothalamic hamartomas: surgical management with special reference to Gamma Knife surgery. Childs Nerv Syst 22:881-895, 2006

22. Rolston JD, Chang EF: Stereotactic laser ablation for hypothalamic hamartoma. Neurosurg Clin N Am 27:59-67, 2016

23. Tovar-Spinoza Z, Carter D, Ferrone D, Eksioglu Y, Huckins
S: The use of MRI-guided laser-induced thermal ablation for epilepsy. Childs Nerv Syst 29:2089-2094, 2013

24. Wilfong AA, Curry DJ: Hypothalamic hamartomas: optimal approach to clinical evaluation and diagnosis. Epilepsia 54 (Suppl 9):109-114, 2013

25. Willie JT, Laxpati NG, Drane DL, Gowda A, Appin C, Hao $\mathrm{C}$, et al: Real-time magnetic resonance-guided stereotactic laser amygdalohippocampotomy for mesial temporal lobe epilepsy. Neurosurgery 74:569-585, 2014

\section{Disclosures}

The authors report the following. Dr. Miller: research support for a different study that uses laser ablation. Dr. Ojemann: ownership in Therma Neuroscience.

\section{Author Contributions}

Conception and design: all authors. Acquisition of data: Buckley. Analysis and interpretation of data: all authors. Drafting the article: Buckley, Wang, Ojemann. Critically revising the article: all authors. Reviewed submitted version of manuscript: all authors. Approved the final version of the manuscript on behalf of all authors: Buckley. Study supervision: Ojemann.

\section{Supplemental Information Previous Presentations}

Portions of this work were presented as an oral presentation at the 44th Annual AANS/CNS Section on Pediatric Neurosurgery, Seattle, Washington, December 10, 2015.

\section{Correspondence}

Robert T. Buckley, Division of Neurological Surgery, Seattle Children's Hospital, 4800 Sand Point Way NE, Seattle, WA 98105.email: robuck@uw.edu. 